\title{
Epigenetic paternal effects as costly, condition-dependent traits
}

\author{
Erin L Macartney $\mathbb{D}^{1} \cdot$ Angela J Crean $\mathbb{D}^{1,2} \cdot$ Russell Bonduriansky ${ }^{1}$
}

Received: 30 October 2017 / Revised: 7 February 2018 / Accepted: 20 April 2018 / Published online: 14 June 2018

(c) The Genetics Society 2018

\begin{abstract}
It is now recognized that post-copulatory traits, such as sperm and ejaculate production can impose metabolic costs, and such traits are therefore expected to exhibit condition-dependent expression, whereby, low condition individuals experience a greater marginal cost of investment compared to high condition individuals. Ejaculates are especially costly in species where males invest in offspring quality through nutrient-rich spermatophores or other seminal nuptial gifts. However, recent evidence shows that, in species where males do not provision females or offspring, males can still influence offspring development through paternal effects mediated by epigenetic factors, such as non-coding RNAs, DNA methylation and chromatin structure. Because such epigenetic paternal effects do not involve the transfer of substantial quantities of resources, such as nutrients, the costs of conferring such effects have not been considered. Here we argue that if selection favours paternal investment in offspring quality through epigenetic factors, then the epigenetic machinery required to bring about such effects may also be expected to evolve strongly condition-dependent expression. We outline indirect evidence suggesting that epigenetic paternal effects could impose substantial metabolic costs, consider the conditions under which selection may act on such effects, and suggest ways to test for differential costs and condition-dependence of these effects. Incorporating epigenetic paternal effects into condition-dependent life history theory will further our understanding of the heritability of fitness and the evolution of paternal investment strategies.
\end{abstract}

\section{Epigenetics and life history}

Recent evidence shows that males across many taxa, including nematodes, insects, fish, and mammals, can influence offspring development and quality through epigenetic factors transferred in the sperm and/or semen (reviewed in Crean and Bonduriansky 2014; Rando 2016; Wang et al. 2017). These epigenetic factors can include small non-coding RNAs (ncRNAs), DNA methylation, and chromatin structure, and all these factors can alter gene expression in developing embryos (e.g., Milekic et al. 2015; Grandjean et al. 2015; Skinner 2016; Klosin et al. 2017).

Modifications of the methylation pattern or differences in chromatin structure of the paternal haploid genome in sperm

Erin L Macartney

e.macartney@unsw.edu.au

1 Evolution and Ecology Research Centre and School of Biological, Earth and Environmental Sciences, UNSW Australia, Sydney, NSW 2052, Australia

2 Sydney School of Veterinary Science, The University of Sydney, Sydney, NSW 2006, Australia can in some cases be retained throughout offspring embryonic development or even into adulthood, affecting important aspects of offspring phenotype and fitness (Guerrero-Bosagna et al. 2010; Manikkam et al. 2012; Vassoler et al. 2012; Kelly 2014; Klosin et al. 2017), and non-coding RNAs (such as miRNAs or tsRNAs) can be transferred to the zygote in the sperm and/or seminal fluid and can also alter gene expression in the offspring (Gapp et al. 2014; Stoeckius et al. 2014; Rodgers et al. 2015; Marré et al. 2016). Moreover, changes in multiple types of epigenetic factors often appear to be involved in paternal effects on offspring fitness. For example, high-fat diets in mice can alter the expression of miRNAs, methylation patterns, and chromatin structure in the paternal germline (Fullston et al. 2013; Duale et al. 2014; Barbosa et al. 2016), and these can then up- or down-regulate gene expression in offspring (affecting genes involved in metabolism, insulin secretion and glucose tolerance, and embryo development) and cause significant reductions in offspring health (e.g., Ng et al. 2010; Binder et al. 2012a, b; Fullston et al. 2013; Mitchell et al. 2017). While these wellcharacterised paternal effects act to reduce offspring fitness, there are many examples of non-genetic paternal effects that have the potential to increase offspring fitness by enhancing 
offspring survival and/or reproductive success (e.g., Bonduriansky and Head 2007; Zajitschek et al. 2017; Crean et al. 2013; Delcurto et al. 2013; Jensen et al. 2014; Evans et al. 2017). Paternal effects with both negative- and positive-effects on offspring fitness can be mediated by similar epigenetic mechanisms. Yet, despite their potential importance, there has been little to no incorporation of epigenetic paternal effects into life history theory.

A central idea in life history theory is that persistent directional selection on fitness-enhancing traits can lead to trait exaggeration and thereby drive up the metabolic cost required to produce the trait. Therefore, the amount of metabolic resources available to an individual (i.e., its condition) is expected to determine the expression of such a costly trait, resulting in condition-dependent trait expression (Andersson 1982; Nur and Hasson 1984; Grafen 1990; Iwasa et al. 1991; Kotiaho 2001; Cotton et al. 2004). Individuals that have fewer metabolic resources (i.e., are in low condition) are less able to invest in costly traits compared to individuals that have more metabolic resources (i.e., are in high condition) — that is, low condition individuals experience a higher marginal cost of trait expression. This theory has been extensively applied to secondary sexual traits, such as displays and weaponry (Moller and Delope 1994; Mappes et al. 1996; Kotiaho 2000; Judge et al. 2008) and, more recently, to post-copulatory traits, such as sperm quality and quantity (reviewed in Fitzpatrick and Lüpold 2014; Lüpold et al. 2016; Godwin et al. 2017) and ejaculate size and composition (Eberhard and Cordero 1995; Linklater et al. 2007; Perry and Tse 2013; Friesen et al. 2015; Bretman et al. 2016; Wigby et al. 2016). All these traits are important for male reproductive success and can therefore be exaggerated by selection.

Selection can also favour paternal investment in offspring quality (Maynard Smith 1977; Clutton-Brock 1991; Sheldon 2002; Requena and Alonzo 2017). The costs and condition-depedence of paternal investment have been examined in species where males directly provision their offspring through paternal care (reviewed in Clutton-Brock 1991; Badyaev and Hill 2002; Kelly and Alonzo 2009), or confer nutrient-rich spermatophores or other types of glandular nuptial gifts to females (Gwynne and Simmons 1990; Michaud et al. 2013; Mirhosseini et al. 2014). Such seminal provisioning is typically associated with the production of very large ejaculates that are expected to require substantial investment of resources and to impose substantial metabolic costs. However, such obvious forms of paternal investment are lacking in most species (Eberhard 1997).

More recently, it has been recognised that paternal investment may extend beyond parental care and nutrient provisioning, with calls to generalize the definition of parental investment beyond a 'nutrition-centric' view to include any investment in an offspring that reduces the parent's ability to invest in future offspring (Royle et al. 2012; also see Trivers 1972). If the molecular mechanisms that mediate the transmission of epigenetic factors from fathers to their offspring are costly to build, maintain and deploy, then epigenetic paternal effects are encompassed by this definition of paternal investment. Below, we argue that epigenetic paternal effects that enhance offspring fitness are indeed likely to be costly, and that such effects should be incorporated into life-history theory as condition-dependent paternal investment traits. In addition to behavioural and nutritional provisioning, males may increase offspring survival and/or reproductive success through investment in molecular processes that shape the epigenome in the paternal germ-line and determine the nature of the epigenetic factors transferred to offspring via the sperm and seminal fluid. This can then provide variation for selection to act on, with the fitter offspring surviving to confer the ability to invest in offspring through such epigenetic molecular mechanisms. Selection for enhanced offspring fitness through epigenetic inheritance may then further drive up the metabolic cost of molecular investment, resulting in strongly condition-dependent investment, like that observed in other fitness-enhancing traits (Moller and Delope 1994; Rowe and Houle 1996; Kotiaho 2000; Perry and Rowe 2010).

Obviously, epigenetic factors transmitted through the germ-line can also mediate maternal effects (reviewed in Aiken et al. (2016)). However, because maternal effects can occur via a wide range of mechanisms, such as the egg cytoplasm, the intrauterine environment, or post-partum provisioning (Champagne 2008), the role of germ-line epigenetic factors can be difficult to establish and such factors are unlikely to constitute a major component of total maternal investment. By contrast, in species where males do not provide parental care or nutritional resources, epigenetic paternal effects are likely to comprise a large share of total paternal investment. We therefore focus our discussion on paternal effects mediated by epigenetic factors.

\section{Is epigenetic machinery costly to build and maintain?}

Several lines of evidence suggest that the cost of maintaining a 'good' epigenetic profile could be substantial, and individuals that are unable to invest in maintaining a good epigenome are likely to produce lower quality offspring. First, changes in chromatin structure, RNA synthesis, DNA methylation and some de-methylation require energetic and material investment in tightly regulated molecular processes. Such processes include histone acetylation, RNA synthesis, and the expression and deployment of DNA 
methyltransferases (DNMTs) and methyl-CpG-binding domain (MBD) proteins. All these processes require ATP to provide energy to build and deploy (Gaal et al. 1997; Amiott and Jaehning 2006; Wellen et al. 2009; Bhutani et al. 2011; Horvath 2013). Therefore, individuals that do not have substantial metabolic reserves may be less able to invest in these metabolic pathways.

The most extensively studied of these epigenetic factors is DNA methylation. In mammals and plants, it has been shown that newly synthesised DNA lacks methylation until maintenance methyltransferases (DNMT1) restore methylation patterns through some type of memory mechanism (Okano et al. 1999; Saze et al. 2003; Kato et al. 2007). Horvath (2013) proposed that a substantial amount of energy is needed to maintain epigenetic stability during the stressful period of development when the rate of cell division is high. This may explain why we see such pronounced effects of males' developmental environment on their subsequent capacity to influence the development of their offspring (Bonduriansky and Head 2007; Burdge et al. 2007; Kaati et al. 2007; Bonduriansky et al. 2016). Horvath (2013) also suggested that constant energy expenditure may be required to maintain epigenetic stability throughout adult life, given that DNMTs need to be deployed to maintain existing methylation patterns. Any perturbations such as stress or exposure to toxins may therefore lead to epigenetic dysregulation.

If both the establishment and maintenance of epigenetic machinery are costly, then environmental conditions both during development and during adult life may be expected to affect the epigenome. Such costs may be expected to apply to the maintenance of the epigenome in the soma as well as the germ-line, where epigenetic changes resulting from environmental perturbations can be transmitted to offspring (Lambrot et al. 2013; Guerrero-Bosagna and Skinner 2014; Kitamura et al. 2015). This could explain why both juvenile and adult environments are sometimes found to influence paternal effects on offspring fitness (Ducatez et al. 2012; Adler and Bonduriansky 2013; Braun and Champagne 2014; Fricke et al. 2015; Macartney et al. 2017). However, some paternal effects could be programmed during a specific ontogenetic phase. For example, if the epigenetic machinery involved in such effects is built during embryonic development, then the nutrient abundance or stress experienced by males during a specific sensitive phase of development could largely determine the paternal effects they will confer as adults if environmental perturbations also disrupt epigenetic regulation of the germ line (e.g. Bonduriansky and Head 2007; Kaati et al. 2007; Macartney et al. 2017).

Hypomethylation and (to a lesser extent) hypermethylation of some sites occur with age throughout the mammalian genome-a process known as the 'epigenetic clock'
(Bellizzi et al. 2012; Horvath 2013; Marttila et al. 2015; Milekic et al. 2015; Breitling et al. 2016). Changes in chromatin structure and RNA transcriptional dysfunction have also been shown to increase with age (reviewed in Ashapkin et al. 2017), and several studies have shown that these epigenetic changes to DNA methylation, chromatin structure and RNA synthesis can be accelerated by stress and toxins (Dick et al. 2014; Duale et al. 2014; Horvath et al. 2014; Beach et al. 2015; Boks et al. 2015; Gao et al. 2016). These changes in epigenetic regulation probably reflect negative effects of age and stress on the epigenetic maintenance system (Bellizzi et al. 2012; Horvath 2013; Breitling et al. 2016). Such epigenetic dysregulation has been demonstrated to occur in the germ-line, as well as the soma (e.g. Lambrot et al. 2013; Duale et al. 2014; Milekic et al. 2015; Rodgers et al. 2015), suggesting that some ageand stress-induced epigenetic changes can be transmitted to offspring through transgenerational epigenetic inheritance (Miller et al. 2010; Danchin et al. 2011; Seong et al. 2011; Jenkins and Carrell 2012; Soubry 2015). Just as individuals that are in high condition can prevent or repair genetic mutations better than individuals in low condition (Agrawal and Wang 2008; Skinner et al. 2015; Skinner 2016), males in high condition may be better able to protect or repair the epigenome of their soma and germ-line from age- and stress-induced dysregulation, and thereby produce offspring of higher quality.

In addition to the energetic costs of investing in protection and repair of the epigenome, the ability to synthesize epigenetic factors can be limited by access to certain biochemicals. For example, methylation requires methyl groups, which are derived from dietary methionine-an amino acid that can be limited by the availability of certain foods (Grandison et al. 2009), and dietary glucose appears to play an important role in histone acetylation which influences chromatin structure (Burdge and Lillycrop 2010). Therefore, access to specific dietary nutrients, as well as metabolic energy can influence and limit the expression of epigenetic factors, and thereby affect the maintenance and repair of the epigenome.

\section{Selection on epigenetic paternal effects}

As with investment in other forms of paternal provisioning, selection for males to invest in offspring quality through epigenetic paternal effects will only occur under certain conditions (Kokko 1999; Kokko and Jennions 2008; West and Capellini 2016; Requena and Alonzo 2017). Selection may occur directly through female mate choice, if females discriminate among males based on an honest signal of paternal epigenetic investment. While male sexual signals typically exhibit condition-dependent expression, some 
components of the male phenotype may specifically reveal male epigenetic quality and such signals should be investigated in the future. Females could evolve preferences based on these signals, and such signaler-receiver coevolution could be prevalent in non-resource-based systems where conventional forms of paternal investment are lacking (Crean et al. 2016).

Selection may also occur indirectly, if the epigenetic paternal effect enhances offspring fitness, such that offspring are more likely to inherit and pass on genetic alleles that cause the development of the required epigenetic machinery. The fitness gains from any form of paternal investment will depend on paternity certainty, which reflects the likelihood of female re-mating and the risk of cuckoldry (i.e., the use of resources provided by one male to enhance the quality of another male's offspring) (e.g. Wickler 1985; Gwynne 1988). When the risk of cuckoldry is high, selection may instead favour males that invest in traits that enhance mating success. However, if paternal investment is conferred through factors transferred within the sperm and associated with paternal DNA (for example, via DNA methylation, chromatin structure, and spermborne ncRNAs), the risk of cuckoldry will be negligible or absent as the epigenetic factors are tied directly to fertilisation. Therefore, paternal investment mediated by spermborne epigenetic factors may be more likely to evolve than other mechanisms of paternal investment (Bonduriansky and Day 2013). Paternal investment though epigenetic factors may therefore be taxonomically widespread.

In particular, males of some species can confer their condition to offspring through epigenetic factors (Bonduriansky and Crean 2017), with high condition males producing better quality offspring relative to low condition males (e.g. Bonduriansky and Head 2007; Delcurto et al. 2013; Evans et al. 2017; Zajitschek et al. 2017). For example, such condition-transfer effects have recently been reported in the guppy Poecilia reticulata, where epigenetic factors attached to the sperm of fathers reared on a highquantity diet produced larger offspring and probably enhanced juvenile survival (Evans et al. 2017). Such effects have also been demonstrated in the neriid fly, Telostylinus angusticollis, where fathers reared on a nutrient-rich diet produce larger offspring (Bonduriansky and Head 2007), likely through epigenetic factors (Crean et al. 2014).

While larger body size may be advantageous across a wide range of environments, males of some species may also anticipate the environment that their offspring are likely to experience and produce offspring that are better suited to that environment ('anticipatory effects') (Marshall and Uller 2007; Burgess and Marshall 2014). For example, Crean et al. (2013) and Jensen et al. (2014) demonstrated anticipatory effects of male environment in a broadcast spawning ascidian (Styela plicata) and marine tubeworm
(Hydroides diramphus) respectively, most likely through epigenetic changes to the sperm. Both condition-transfer and anticipatory effects can enhance offspring fitness, providing an indirect benefit to the father and generating positive selection on the cellular and physiological mechanisms involved in the paternal effect. Both conditiontransfer and anticipatory effects are also likely to be costly for males, requiring the synthesis, maintenance and deployment of epigenetic factors that alter offspring development.

Conversely, epigenetic paternal effects can be detrimental. As mentioned previously, stressed or senescent individuals can undergo epigenetic dysregulation (Jirtle and Skinner 2007; Horvath 2013), and transmit some of these epigenetic changes to their offspring (e.g. Rassoulzadegan et al. 2006; Manikkam et al. 2012; Weyrich et al. 2016). This can then result in offspring with decreased health and increased susceptibility to disease (Miller et al. 2010; Danchin et al. 2011; Seong et al. 2011; Jenkins and Carrell 2012; Rando 2012; Soubry 2015). Marshall and Uller (2007) suggest that such 'transmissive' effects occur due to physiological constraints on the expression of reproductive traits. Therefore, selection should favour males that are able to overcome such physiological constraints by investing more metabolic resources in maintaining a healthy germline epigenome to produce healthier offspring. High condition individuals possess more metabolic resources and may therefore be better able to prevent transmissive effects by investing in costly molecular mechanisms that protect or repair the epigenome.

\section{Predictions and empirical tests}

There is currently a dearth of empirical and theoretical work directly exploring the costs and condition-dependence of investment in epigenetic factors, including the molecular machinery involved in non-genetic paternal effects. Two important questions that require empirical research and that are key to furthering our understanding of the evolution and ecology of paternal effects mediated by epigenetic factors are: (1) Under what conditions does selection favour male ability to influence offspring quality through transmission of beneficial epigenetic factors via the germ-line and/or through suppression of detrimental epigenetic effects?; and (2) does investment in epigenetic paternal effects result in life-history trade-offs similar to the trade-offs that limit investment in other costly reproductive traits?

To address question (1), it is necessary to determine whether males that confer positive epigenetic effects through their germ-line have higher fitness than males that do not confer such effects, and whether variation in the ability to confer such paternal effects is heritable. If both 
conditions are met, then the ability to confer such epigenetic effects to offspring may be expected to evolve. It would also be interesting to determine whether females preferentially mate with males that produce better quality offspring via such epigenetic effects, given that female preferences could contribute to selection on males to confer such effects (Bonduriansky and Day 2013; Bonilla et al. 2016; Head et al. 2016). For example, a model by Bonduriansky and Day (2013) showed that paternal condition-transfer effects in species where males do not provide conventional forms of paternal provisioning could drive the evolution of costly female mate choice. Such female preferences could drive increased male investment in offspring quality. Importantly, given the potential for epigenetic paternal effects, the evolution of paternal investment can occur in species where opportunity for conventional forms of paternal investment (such as paternal care or nutrient-laden nuptial gifts) is lacking. For example, such effects can evolve in species such as guppies (Evans et al. 2017) and neriid flies (Bonduriansky and Head 2007) or in broadcast spawning species (Crean et al. 2013; Jensen et al. 2014), where males transfer small ejaculates and do not interact with their offspring.

Regarding question (2), if investment in offspring quality through epigenetic factors carries a substantial metabolic cost, then such investment may be predicted to respond to variation in the availability of metabolic resources, and to trade-off against investment in other costly fitness components, as predicted by life history theory (Stearns 1989; Zera and Harshman 2001; Roff and Fairbairn 2007). For example, we might expect to see a decline in offspring quality with increased mating (or an increase in other costly lifehistory traits that may trade-off with investment in offspring) due to a reduction in the ability to maintain the synthesis and/or maintenance of epigenetic factors in the germ-line. We may also expect to see a steeper decline in offspring quality in low condition individuals compared to high condition individuals if investing in these factors is condition-dependent. This has been demonstrated in males that produce spermatophores: in such species, depletion of male stores through repeated mating can reduce spermatophore size (Rutowski 1979; Marcotte et al. 2007; Michaud et al. 2013) and alter offspring development (Michaud et al. 2013; Mirhosseini et al. 2014). However, such reductions in offspring quality have not yet been demonstrated in species where paternal effects on offspring performance are mediated by epigenetic factors. We may also expect to see a trade-off with other life-history traits, such as somatic maintenance and lifespan, as observed in males that transfer costly spermatophores (Mishra and Omkar 2006; Perry and Tse 2013). However, in order to directly test for costs of investment in epigenetic factors, and determine whether investment is condition-dependent (i.e., whether investment involves differential marginal costs to high condition vs. low condition males), male condition and the expression of the epigenetic factors that mediate paternal effects will need to be manipulated (as suggested by Kotiaho (2001) in relation to the costs and condition-dependence of secondary sexual traits).

Epigenetic factors could be manipulated by creating 'knockout' lines for particular RNAs, administering oligonucleotides or synthesized RNAs, or by using CRISPR-Cas based tools (e.g. Vasudevan et al. 2007; McDonald et al. 2016; Abudayyeh et al. 2016). These approaches may allow researchers to experimentally up- or down-regulate the expression of specific epigenetic factors involved in paternal effects or epigenetic regulation systems such as DNMT1s that maintain epigenetic integrity, and then measure how males of different condition respond to changes in such factors. For example, if the expression of an epigenetic factor is upregulated, we may expect males of low condition to suffer a steeper decline in other life-history traits because of the higher marginal costs of investment in the epigenetic machinery. We may also detect an exaggerated decline in other life-history traits if the epigenetic machinery is upregulated in older individuals, since older individuals may suffer a larger marginal cost of maintaining epigenetic integrity relative to young individuals. These effects are likely to interact, such that the effect of old age is accentuated by low condition. Such experiments would make it possible to test for differential costs of investment in epigenetic paternal effects, and potentially make it possible to quantify such costs.

\section{Conclusion}

Establishing to what extent paternal effects transmitted through epigenetic factors function as costly and conditiondependent life-history traits requires additional theoretical and empirical work, and will necessitate overcoming some practical challenges. Progress will require an understanding of when investment in the epigenetic machinery occurs (i.e., are the key epigenetic systems built during juvenile development, or during the adult stage?), knowing what epigenetic factors are involved in influencing offspring quality in specific study species, as well as the ability to manipulate individual condition and investment in epigenetic factors that mediate paternal effects. Although, the technology available for direct manipulation of epigenetic mechanisms is currently limited, it is progressing at a rapid rate (e.g., Frye et al. 2016; McDonald et al. 2016; Abudayyeh et al. 2016; Pulecio et al. 2017). And while we have focused on the most widely studied epigenetic factors (DNA methylation, ncRNAs and chromatin structure), the sperm and semen also contain many other non-genetic factors (such as cytoplasmic and accessory-gland proteins) that are not 
conventionally regarded as forms of nutrient provisioning or categorized as instances of transgenerational epigenetic inheritance, but that could nonetheless influence offspring development.

Understanding the differential costs and condition dependence of non-genetic paternal effects mediated by epigenetic factors will make it possible to extend life history theory to encompass this poorly understood facet of male reproductive strategies. Understanding such effects will also shed light on a potentially important component of variation in offspring performance, and a potential factor in the evolution of female mate choice. Moreover, epigenetic paternal effects could provide a valuable opportunity to investigate the costs of building, maintaining and deploying various types of epigenetic machinery-a question that remains almost entirely unexplored.

Acknowledgements We would like to thank Amy K. Hooper, Nathan W. Burke and Zachariah Wylde, the delegates from the Evolutionary Society for Evolutionary Biology and the Biology of Spermatozoa meetings, and the reviewers and editors for their valuable comments and suggestions.

\section{Compliance with ethical standards}

Conflict of interest The authors declare that they have no conflict of interest.

\section{References}

Abudayyeh OO, Gootenberg JS, Konermann S, Joung J, Slaymaker IM, Cox DBT et al. (2016) C2c2 is a single-component programmable RNA-guided RNA-targeting CRISPR effector. Science 353:5571-5579

Adler MI, Bonduriansky R (2013) Paternal effects on offspring fitness reflect father's social environment. Evol Biol 40:288-292

Agrawal AF, Wang AD (2008) Increased transmission of mutations by low-condition females: Evidence for condition-dependent DNA repair. PLoS Biol 6:0389-0395

Aiken CE, Tarry-Adkins SE, Ozanne JL. (2016) Transgenerational effects of maternal diet on metabolic and reproductive ageing. Mamm Genome 27:430-439

Amiott EA, Jaehning JA (2006) Mitochondrial transcription is regulated via an ATP 'sensing' mechanism that couples RNA abundance to respiration. Mol Cell 22:329-338

Andersson M (1982) Sexual selection, natural selection, and quality advertisement. Biol J Linn Soc 82:375-393

Ashapkin VV, Kutaeva LI, Vanyushin BF (2017) Aging as an epigenetic phenomenon. Curr Genom 18:385-407

Badyaev AV, Hill GE (2002) Paternal care as a conditional strategy: distinct reproductive tactics associated with elaboration of plumage ornamentation in the house finch. Behav Ecol 13:591-597

Barbosa TD, Ingerslev LR, Alm PS, Versteyhe S, Massart J, Rasmussen $M$ et al. (2016) High-fat diet reprograms the epigenome of rat spermatozoa and transgenerationally affects metabolism of the offspring. Mol Metab 5:184-197

Beach SRH, Dogan MV, Lei M, Cutrona CE, Gerrard M, Gibbons FX et al. (2015) Methylomic aging as a window onto the influence of lifestyle: tobacco and alcohol use alter the rate of biological aging. J Am Geriatr Soc 63:2519-2525

Bellizzi D, D’Aquila P, Montesanto A, Corsonello A, Mari V, Mazzei B et al. (2012) Global DNA methylation in old subjects is correlated with frailty. Age 34:169-179

Bhutani N, Burns DM, Blau HM (2011) DNA demethylation dynamics. Cell 146:866-872

Binder NK, Hannan NJ, Gardner DK (2012a) Paternal diet-induced obesity retards early mouse embryo development, mitochondrial Aactivity and pregnancy health. PLoS ONE 7:e52304

Binder NK, Mitchell M, Gardner DK (2012b) Parental diet-induced obesity leads to retarded early mouse embryo development and altered carbohydrate utilisation by the blastocyst. Reprod Fertil Dev 24:804-812

Boks MP, Van Mierlo HC, Rutten BPF, Radstake TRDJ, De Witte L, Geuze E et al. (2015) Longitudinal changes of telomere length and epigenetic age related to traumatic stress and post-traumatic stress disorder. Psychoneuroendocrinology 51:506-512

Bonduriansky R, Crean AJ (2017) What are parental condition-transfer effects and how can they be detected? Methods Ecol Evol 9:1-7

Bonduriansky R, Day T (2013) Nongenetic inheritance and the evolution of costly female preference. J Evol Biol 26:76-87

Bonduriansky R, Head M (2007) Maternal and paternal condition effects on offspring phenotype in Telostylinus angusticollis (Diptera: Neriidae). J Evol Biol 20:2379-2388

Bonduriansky R, Runagall-McNaull A, Crean AJ (2016) The nutritional geometry of parental effects: maternal and paternal macronutrient consumption and offspring phenotype in a neriid fly. Funct Ecol 30:1675-1686

Bonilla MM, Zeh JA, Zeh DW (2016) An epigenetic resolution of the lek paradox. Bioessays 38:355-366

Braun K, Champagne FA (2014) Paternal influences on offspring development: behavioural and epigenetic pathways. J Neuroendocrinol 26:697-706

Breitling LP, Saum KU, Perna L, Schottker B, Holleczek B, Brenner H (2016) Frailty is associated with the epigenetic clock but not with telomere length in a German cohort. Clin Epigenetics 8:21

Bretman A, Fricke C, Westmancoat JD, Chapman T (2016) Effect of competitive cues on reproductive morphology and behavioral plasticity in male fruitflies. Behav Ecol 27:452-461

Burdge GC, Lillycrop KA (2010) Nutrition, epigenetics, and developmental plasticity: implications for understanding human disease. Annu Rev Nutr 30:315-339

Burdge GC, Slater-Jefferies J, Torrens C, Phillips ES, Hanson MA, Lillycrop KA (2007) Dietary protein restriction of pregnant rats in the F0 generation induces altered methylation of hepatic gene promoters in the adult male offspring in the F1 and F2 generations. Br J Nutr 97:435-439

Burgess SC, Marshall DJ (2014) Adaptive parental effects: the importance of estimating environmental predictability and offspring fitness appropriately. Oikos 123:769-776

Champagne FA (2008) Epigenetic mechanisms and the transgenerational effects of maternal care. Front Neuroendocrinol 29:386-397

Cotton S, Fowler K, Pomiankowski A (2004) Do sexual ornaments demonstrate heightened condition-dependent expression as predicted by the handicap hypothesis? Proc Biol Sci 271:771-783

Crean AJ, Adler MI, Bonduriansky R (2016) Seminal fluid and mate choice: New predictions. Trends Ecol Evol 31:253-255

Crean AJ, Bonduriansky R (2014) What is a paternal effect? Trends Ecol Evol 29:554-559

Crean AJ, Dwyer JM, Marshall DJ (2013) Adaptive paternal effects? Experimental evidence that the paternal environment affects offspring performance. Ecology 94:2575-2582

Crean AJ, Kopps AM, Bonduriansky R (2014) Revisiting telegony: offspring inherit an acquired characteristic of their mother's previous mate. Ecol Lett 17:1545-1552 
Clutton-Brock TH (1991) The Evolution of Parental Care.. Princeton University Press, Princeton, New Jersey

Danchin E, Charmantier A, Champagne FA, Mesoudi A, Pujol B, Blanchet S (2011) Beyond DNA: integrating inclusive inheritance into an extended theory of evolution. Nat Rev Genet $12: 475-486$

Delcurto H, Wu G, Satterfield MC (2013) Nutrition and reproduction: links to epigenetics and metabolic syndrome in offspring. Curr Opin Clin Nutr Metab Care 16:385-391

Dick KJ, Nelson CP, Tsaprouni L, Sandling JK, Aïssi D, Wahl S et al. (2014) DNA methylation and body-mass index: a genome-wide analysis. Lancet 383:1990-1998

Duale N, Steffensen I, Andersen J, Brevik A, Brunborg G, Lindeman B (2014) Impaired sperm chromatin integrity in obese mice. Andrology 2:234-243

Ducatez S, Baguette M, Stevens VM, Legrand D, Fr H (2012) Complex interactions betweem paternal and materanal effects: Parental experience and age at reproduction affect fecundity and offspring performance in a butterfly. Evolution 66:3558-3569

Eberhard WG (1997) Sexual selection by cryptic female choice in insects and arachnids. In: Chloe JC, Crepsi BJ (eds) The Evolution of mating Systems in Insects and Arachnids. Cambridge University Press, Cambridge, p 32-57

Eberhard WG, Cordero C (1995) Sexual selection by cryptic female choice on male seminal products - a new bridge between sexual selection and reproductive physiology. Trends Ecol Evol 10:493-496

Evans JP, Lymbery RA, Wiid KS, Rahman M, Gasparini C (2017) Sperm as moderators of environmentally induced paternal effects in a livebearing fish. Biol Lett 13:10-13

Fitzpatrick JL, Lüpold S (2014) Sexual selection and the evolution of sperm quality. Mol Hum Reprod 20:1180-1189

Fricke C, Adler MI, Brooks RC, Bonduriansky R (2015) The complexity of male reproductive success: effects of nutrition, morphology, and experience. Behav Ecol 26:617-624

Friesen CR, Powers DR, Copenhaver PE, Mason RT (2015) Size dependence in non-sperm ejaculate production is reflected in daily energy expenditure and resting metabolic rate. J Exp Biol 218:1410-1418

Frye M, Jaffrey SR, Pan T, Rechavi G, Suzuki T (2016) RNA modifications: what have we learned and where are we headed? Nat Rev Genet 17:365-372

Fullston T, Teague EMCO, Palmer NO, Deblasio MJ, Mitchell M, Corbett $\mathrm{M}$ et al. (2013) Paternal obesity initiates metabolic disturbances in two generations of mice with incomplete penetrance to the F 2 generation and alters the transcriptional profile of testis and sperm microRNA content. FASEB J 27:4226-4243

Gaal T, Bartlett MS, Ross W, Turnbough CL, Gourse RL (1997) Transcription regulation by initiating NTP concentration: rRNA synthesis in bacteria. Science 278:2092-2097

Gao X, Zhang Y, Breitling LP, Brenner H (2016) Relationship of tobacco smoking and smoking-related DNA methylation with epigenetic age acceleration. Oncotarget 7:46878-46889

Gapp K, Jawaid A, Sarkies P, Bohacek J, Pelczar P, Prados J et al. (2014) Implication of sperm RNAs in transgenerational inheritance of the effects of early trauma in mice. Nat Neurosci 17:667-669

Godwin JL, Vasudeva R, Michalczyk L, Martin OY, Lumley AJ, Chapman $\mathrm{T}$ et al. (2017) Experimental evolution reveals that sperm competition intensity selects for longer, more costly sperm. Evol Lett 1:102-113

Grafen A (1990) Biological signals as handicaps. J Theor Biol 144:517-546

Grandison RC, Piper MDW, Partridge L (2009) Amino-acid imbalance explains extension of lifespan by dietary restriction in Drosophila. Nature 462:1061-1065
Grandjean V, Fourre S, De Abreu DAF, Derieppe MA, Remy JJ, Rassoulzadegan M (2015) RNA-mediated paternal heredity of diet-induced obesity and metabolic disorders. Sci Rep 5:18193

Guerrero-Bosagna C, Settles M, Lucker B, Skinner MK (2010) Epigenetic transgenerational actions of vinclozolin on promoter regions of the sperm Eepigenome. PLoS ONE 5:1-17

Guerrero-Bosagna C, Skinner MK (2014) Environmentally induced epigenetic transgenerational inheritance of male infertility. Curr Opin Genet Dev 26:79-88

Gwynne DT (1988) Courtship feeding in katydids benefits the mating male's offspring. Behav 23:373-377

Gwynne DT, Simmons LW (1990) Experimental reversal of courtship roles in an insect. Nature 346:172-174

Head ML, Jennions MD, Zajitschek SRK (2016) Sexual selection: incorporating non-genetic inheritance. Curr Opin Behav Sci 12:129-137

Horvath S (2013) DNA methylation age of human tissues and cell types. Genome Biol 14:R115

Horvath S, Erhart W, Brosch M, Ammerpohl O, Von Schönfels W, Ahrens $M$ et al. (2014) Obesity accelerates epigenetic aging of human liver. Proc Natl Acad Sci USA 111:15538-15543

Iwasa Y, Pomiankowski A, Nee S (1991) The Evolution of Costly Mate Preferences II. The 'Handicap' Principle. Evolution 45:1431

Jenkins TG, Carrell DT (2012) The sperm epigenome and potential implications for the developing embryo. Reproduction 143:727-734

Jensen N, Allen RM, Marshall DJ (2014) Adaptive maternal and paternal effects: gamete plasticity in response to parental stress. Funct Ecol 28:724-733

Jirtle RL, Skinner MK (2007) Environmental epigenomics and disease susceptibility. Nat Rev Genet 8:253-262

Judge KA, Ting JJ, Gwynne DT (2008) Condition dependence of male life span and calling effort in a field cricket. Evolution 62:868-878

Kaati G, Bygren LO, Pembrey M, Sjo M (2007) Transgenerational response to nutrition, early life circumstances and longevity. Eur J Hum Genet 15:784-790

Kato Y, Kaneda M, Hata K, Kumaki K, Hisano M, Kohara Y et al. (2007) Role of the Dnmt3 family in de novo methylation of imprinted and repetitive sequences during male germ cell development in the mouse. Hum Mol Genet 16:2272-2280

Kelly WG (2014) Transgenerational epigenetics in the germline cycle of Caenorhabditis elegans. Epigenetics Chromatin 7:6

Kelly NB, Alonzo SH (2009) Will male advertisement be a reliable indicator of paternal care, if offspring survival depends on male care? Proc R Soc B Biol Sci 276:3175-3183

Kitamura A, Miyauchi N, Hamada H, Hiura H, Chiba H, Okae H et al. (2015) Epigenetic alterations in sperm associated with male infertility. Congenit Anom 55:133-144

Klosin A, Casas E, Hidalgo-Carcedo C, Vavouri T, Lehner B (2017) Transgenerational transmission of environmental information in C. elegans. Science 356:320-323

Kokko H (1999) Cuckoldry and the stability of biparental care. Ecol Lett 2:247-255

Kokko H, Jennions MD (2008) Parental investment, sexual selection and sex ratios. J Evol Biol 21:919-948

Kotiaho JS (2000) Testing the assumptions of conditional handicap theory: costs and condition dependence of a sexually selected trait. Behav Ecol Sociobiol 48:188-194

Kotiaho JS (2001) Costs of sexual traits: a mismatch between theoretical considerations and empirical evidence. Biol Rev 76:365-376

Lambrot R, Xu C, Saint-Phar S, Chountalos G, Cohen T, Paquet M et al. (2013) Low paternal dietary folate alters the mouse sperm epigenome and is associated with negative pregnancy outcomes. Nat Commun 4:2889 
Linklater JR, Wertheim B, Wigby S, Chapman T (2007) Ejaculate depletion patterns evolve in response to experimental manipulation of sex ratio in Drosophila melanogaster. Evolution 61:2027-2034

Lüpold S, Manier MK, Puniamoorthy N, Schoff C, Starmer WT, Luepold SHB et al. (2016) How sexual selection can drive the evolution of costly sperm ornamentation. Nature 533:535-538

Macartney EL, Crean AJ, Bonduriansky R (2017) Adult dietary protein has age- and context-dependent effects on male postcopulatory performance. J Evol Biol 38:42-49

Manikkam M, Guerrero-Bosagna C, Tracey R, Haque M, Skinner MK (2012) Transgenerational actions of environmental compounds on reproductive disease and identification of epigenetic biomarkers of ancestral exposures. PLoS ONE 7:e31901

Mappes J, Alatalo RV, Kotiaho J, Parri S (1996) Viability costs of condition-dependent sexual male display in a drumming wolf spider. Proc R Soc B 263:785-789

Marcotte M, Delisle J, McNeil JN (2007) Effects of different male remating intervals on the reproductive success of Choristoneura rosaceana males and females. J Insect Physiol 53:139-145

Marré J,Traver EC,Jose AM,(2016) Extracellular RNA is transported from one generation to the next in Caenorhabditis elegans Proc Natl Acad Sci USA 113:12496-12501

Marshall DJ, Uller T (2007) When is a maternal effect adaptive? Oikos 116:1957-1963

Marttila S, Kananen L, Häyrynen S, Jylhävä J, Nevalainen T, Hervonen A et al. (2015) Ageing-associated changes in the human DNA methylome: genomic locations and effects on gene expression. BMC Genom 16:1-17

Maynard Smith J (1977) Parental investment: a prospective analysis. Anim Behav 25:1-9

McDonald JI, Celik H, Rois LE, Fishberger G, Fowler T, Rees R et al. (2016) Reprogrammable CRISPR/Cas9-based system for inducing site-specific DNA methylation. Biol Open 5:866-874

Michaud JP, Bista M, Mishra G, Singh O (2013) Sexual activity diminishes male virility in two Coccinella species: consequences for female fertility and progeny development. Bull Entomol Res 103:570-577

Milekic MH, Xin Y, Donnell AO, Kumar KK, Malaspina D, Moore H et al. (2015) Age-related sperm DNA methylation changes are transmitted to offspring and associated with abnormal behavior and dysregulated gene expression. Mol Psychiatry 20:995-1001

Miller D, Brinkworth M, Iles D (2010) Paternal DNA packaging in spermatozoa: more than the sum of its parts? DNA, histones, protamines and epigenetics. Reproduction 139:287-301

Mirhosseini MA, Michaud JP, Jalali MA, Ziaaddini M (2014) Paternal effects correlate with female reproductive stimulation in the polyandrous ladybird Cheilomenes sexmaculata. Bull Entomol Res 104:480-485

Mishra G, Omkar (2006) Ageing trajectory and longevity trade-off in an aphidophagous ladybird, Propylea dissecta (Coleoptera: Coccinellidae). Eur J Entomol 103:33-40

Mitchell M, Strick R, Strissel PL, Dittrich R, Mcpherson NO, Lane M et al. (2017) Gene expression and epigenetic aberrations in F1placentas fathered by obese males. Mol Reprod Dev 84:316-328

Moller AP, Delope F (1994) Differential costs of a secondary sexual character - an experimental test of the handicap principle. Evolution 48:1676-1683

Ng S-F, Lin RCY, Laybutt DR, Barres R, Owens JA, Morris MJ (2010) Chronic high-fat diet in fathers programs $\beta$-cell dysfunction in female rat offspring. Nature 467:963-966

Nur N, Hasson O (1984) Phenotypic plasticity and the handicap principle. J Theor Biol 110:275-297

Okano M, Bell DW, Haber DA, Li E (1999) DNA methyltransferases Dnmt3a and Dnmt3b are essential for de novo methylation and mammalian development. Cell 99:247-257
Perry JC, Rowe L (2010) Condition-dependent ejaculate size and composition in a ladybird beetle. Proc R Soc B Biol Sci 277:3639-3647

Perry JC, Tse CT (2013) Extreme costs of mating for male two-spot ladybird beetles. PLoS ONE 8:e81934

Pulecio J, Verma N, Mejia-Ramıres E, Huangfu D, Raya A (2017) Protocol review CRISPR/Cas9-based engineering of the epigenome. Cell Stem Cell 21:431-447

Rando OJ (2012) Daddy issues: paternal effects on phenotype. Cell 151:702-708

Rando OJ (2016) Intergenerational transfer of epigenetic information in sperm. Cold Spring Harb Perspect Biol 6:1-14

Rassoulzadegan M, Grandjean V, Gounon P, Vincent S, Gillot I, Cuzin F (2006) RNA-mediated non-mendelian inheritance of an epigenetic change in the mouse. Nature 441:469-474

Requena GS, Alonzo SH (2017) Sperm competition games when males invest in paternal care. Proc R Soc B 284:1-9

Rodgers AB, Morgan CP, Leu NA, Bale TL (2015) Transgenerational epigenetic programming via sperm microRNA recapitulates effects of paternal stress. Proc Natl Acad Sci USA 112:13699-13704

Roff DA, Fairbairn DJ (2007) The evolution of trade-offs: where are we? J Evol Biol 20:433-447

Rowe L, Houle D (1996) The lek paradox and the capture of genetic variance by condition dependent traits. Proc R Soc B Biol Sci 263:1415-1421

Royle NJ, Smiseth PT, Kölliker M (2012) The Evolution of Parental Care. Oxford University Press: Oxford, United Kingdom.

Rutowski RL (1979) Butterfly as an honest salesman. Anim Behav 27:1269-1270

Saze H, Mittelsten Scheid O, Paszkowski J (2003) Maintenance of $\mathrm{CpG}$ methylation is essential for epigenetic inheritance during plant gametogenesis. Nat Genet 34:65-69

Seong KH, Li D, Shimizu H, Nakamura R, Ishii S (2011) Inheritance of stress-induced, ATF-2-dependent epigenetic change. Cell 145:1049-1061

Sheldon BC (2002) Relating paternity to paternal care. Philos Trans R Soc B Biol Sci 357:341-350

Skinner MK (2016) Epigenetic transgenerational inheritance. Nat Rev 12:68-70

Skinner MK, Guerrero-Bosagna C, Haque MM (2015) Environmentally induced epigenetic transgenerational inheritance of sperm epimutations promote genetic mutations. Epigenetics 10:762-771

Soubry A (2015) Epigenetic inheritance and evolution: a paternal perspective on dietary influences. Prog Biophys Mol Biol 118:79-85

Stearns SC (1989) Trade-offs in life history evolution. Funct Ecol 3:259-268

Stoeckius M, Grün D, Rajewsky N (2014) Paternal RNA contributions in the Caenorhabditis elegans zygote. EMBO J 33:1740-1750

Thornhill R (1976) Sexual selection and paternal investment in insects. Am Nat 110:153-163

Trivers RL (1972) Parental investment and sexual selection. In: Campbell B (ed) Sexual Selection and the Descent of Man. Aldeline Press, Chicago, p 136-179

Vassoler FM, White SL, Schmidt HD, Sadri-Vakili G, Pierce RC (2012) Epigenetic inheritance of a cocaine-resistance phenotype. Nat Neurosci 16:42-47

Vasudevan S, Tong Y, Steitz JA (2007) Switching from repression to activation: MicroRNAs can up-regulate translation. Science 318:1931-1934

Wang Y, Liu H, Sun Z (2017) Lamarck rises from his grave: parental environment-induced epigenetic inheritance in model organisms and humans. Biol Rev 92:2084-2111

Wellen KE, Hatzivassiliou G, Sachdeva UM, Bui TV, Cross R, Thompson CB et al. (2009) ATP-citrate lyase links cellular metabolism to histone acetylation. Science 324:1076-1080 
West HER, Capellini I (2016) Male care and life history traits in mammals. Nat Commun 7:1-10

Weyrich A, Lenz D, Jeschek M, Chung TH, Rübensam K, Göritz F et al. (2016) Paternal intergenerational epigenetic response to heat exposure in male Wild Guinea pigs. Mol Ecol 25:1729-1740

Wickler W (1985) Stepfathers in insects and their pseudo-parental investment. Z Tierpsychol 69:72-78
Wigby S, Perry JC, Kim YH, Sirot LK (2016) Developmental environment mediates male seminal protein investment in Drosophila melanogaster. Funct Ecol 30:410-419

Zajitschek F, Zajitschek S, Manier M (2017) High-protein paternal diet confers an advantage to sons in sperm competition. Biol Lett $13: 1-5$

Zera AJ, Harshman LG (2001) The physiology of life history tradeoffs in animals. Annu Rev Ecol Syst 32:95-126 